\title{
Temporal/locative inversion in Arabic
}

\author{
Marwan Jarrah \\ Newcastle University \\ m.a.s.jarrah@ncl.ac.uk
}

\begin{abstract}
This research scrutinizes the observation that when the thematic subject is extracted (i.e. questioned) in Jordanian Arabic, temporal/locative inversion may occur. Temporal inversion occurs irrespective of the verb being transitive or intransitive, whereas locative inversion is limited to contexts with an unaccusative verb. This research argues that this distinction correlates with the base-generation of temporal/locative adjuncts; temporal adjuncts are base-generated adjoining to TP, whereas locatives are base-generated adjoining to VP. Temporal but not locative adjuncts resist fronting with vP, demand the use of a tense copula (or a tensed verb), and are not subject to deletion along with the lexical verb. With the assumption that Spec, SubjP must be filled with a non-silent copy due to the effects of the so-called Subject Criterion (Rizzi and Shlonsky 2007), a temporal or locative adjunct, if any, fills this position instead of the extracted thematic subject. Given its low position, a locative adjunct is accessible to $\mathrm{Subj}^{0}$ only when there is no $\mathrm{v}^{*} \mathrm{P}$, hence the account of the correlation between locative inversion and the type of the verb. Furthermore, this research explores the existence of temporal/locative inversion in other two Arabic dialects (Najdi Arabic and Iraqi Arabic), arguing for a micro-parametric view of this strategy across Arabic dialects.
\end{abstract}

Keywords: Arabic: Phase Theory: subject extraction: temporal/locative inversion.

\section{Introduction}

In Jarrah (2017), I argue that the extracted subject in Jordanian Arabic (JA) does not land in Spec, SubjP (a mnemonic for Subject Phrase, a separate layer dominating TP but c-commanded by CP; cf. Cardinaletti 2004) through its journey to the left periphery. ${ }^{1,2}$ I argue that Spec, SubjP in this Arabic variety is a criterial

\footnotetext{
${ }^{1}$ I would like to thank two anonymous reviewers of Yearbook of the Poznan Linguistic Meeting for their valuable feedback. I would also like to thank my postgraduate fellows Eisa Al-Rasheedi and Murdhy Al-Shamari for Najdi Arabic data and Ekhlas Ali Mohsin for Iraqi Arabic data.

${ }^{2}$ Subject extraction refers here to cases where the subject is questioned as in Who left home late?.
} 
position in the sense of Rizzi $(2005,2010,2014)$ and Rizzi and Shlonsky (2007). As such, any phrase occupying this position is trapped in place and becomes unable to escape. I further argue that in order to facilitate subject extraction, Spec, SubjP is filled with either the D(iscourse)-linking particle Pilli, a deictic locative/temporal, or a pro, depending on whether the subject wh-word is D-linked or not. Consider the following examples:

$$
\begin{array}{lll}
\text { miin } *(\text { Pilli) } & \text { Paхað-t } & \text { Pal-mafatiit? } \\
\text { who Prt } & \text { took-3SG.F } & \text { DEF-keys }
\end{array}
$$

'Who took the keys?'

\begin{tabular}{|c|c|}
\hline $\begin{array}{l}\text { miin Pimbaariћ ?a } \\
\text { who yesterday to } \\
\text { 'Who took the keys ye }\end{array}$ & $\begin{array}{ll} & \text { Pal-mafatiih? } \\
\text { SG.F } & \text { DEF-keys } \\
\text { lay?' } & \end{array}$ \\
\hline $\begin{array}{l}\text { miin bi-d-dukaanah } \\
\text { who in-DEF-shop } \\
\text { 'Who fell down in the }\end{array}$ & $\begin{array}{l}\text { wigh-at? } \\
\text { fall down-3SG.F } \\
\text { on?' }\end{array}$ \\
\hline $\begin{array}{l}\text { miin Paхað } \\
\text { who took.3SG.M } \\
\text { 'Who took the keys?' }\end{array}$ & $\begin{array}{l}\text { nafatiii? } \\
\text {-keys }\end{array}$ \\
\hline
\end{tabular}

In all examples in (1), the subject is extracted to the left periphery. ${ }^{3}$ In (1a), Spec, SubjP is filled with Pilli, whereas it is filled with the deictic temporal adjunct Pimbaarih in (1b) and the locative adjunct biddukaanah in (1c). Spec, SubjP is filled with a non-referential (i.e. expletive) pro in (1d). ${ }^{4}$ The subject wh-word in $(1 \mathrm{a}-\mathrm{c})$ is D-linked as it implies the existence of a set of contextually determined entities from which the speaker is asking for a choice (see Fernández 2009), hence the use of Pilli or a temporal/locative adjunct in Spec, SubjP. ${ }^{5}$ Most relevant here is the observation that temporal inversion is indifferent to the

\footnotetext{
${ }^{3}$ See, Jarrah (2017) for several pieces of evidence that the subject is actually in the left periphery in examples like (1).

${ }^{4}$ Note here that the assumption that an expletive pro occupies Spec, SubjP in (1d) is consistent with Rizzi and Shlonsky's (2007) proposal that Spec, SubjP may be filled with an expletive pro in pro-drop languages like Italian. There is no obvious reason that this proposal should not carry over to JA, another true instance of a pro-drop language.

${ }^{5}$ In Jarrah (2017), I argue that the use of the D-linking particle Pilli or a deictic temporal/locative adjunct follows from a condition operating in JA that demands Spec, SubjP be filled with an element with the same D-linking status as the Subject wh-word.
} 
type of the verb (i.e. transitive vs. intransitive), whereas locative inversion is subject to the type of the verb, i.e. just occurs in questions with unaccusative predicates. In Jarrah (2017), I suggest that this follows from the base-generation of temporal and locative adjuncts. Temporal adjuncts are VP-external adjuncts (i.e. TP-adjuncts), whereas locatives are VP-internal adjuncts. This assumption was adopted with no evidence corroborating it. Furthermore, there is no examination of relevant facts from other Arabic dialects. Against this background, the current research aims to provide empirical evidence from three Arabic dialects supporting the view that temporal adjuncts in Arabic are base-generated adjoining to TP, whereas locatives are based-generated adjoining to VP.

Section 2 provides a background overview of subject extraction in Arabic in addition to my (2017) account of the main observations related to this phenomenon in JA. Section 3 provides empirical evidence to the effect that temporal adjuncts are adjoined to TP, while locatives are adjoined to VP. The evidence draws on facts from dislocation, coordination, and ellipsis. Section 4 explores to what extent other Arabic dialects behave similarly with respect to temporal/locative inversion with the presence of subject extraction. This section shows that temporal/locative inversion is subject to micro-parametric variation across Arabic dialects. Section 5 concludes the research.

\section{Subject extraction in Arabic}

Several works have shown that when the subject is extracted (questioned) in Arabic, there are certain effects that occur in response to subject extraction. One of these effects is the (optional) use of the word Pilli that appears between the subject wh-word and the verb. Consider the following examples from Palestinian Arabic, reported in Shlonsky (2002: 142), as in (2). ${ }^{6}$

(2a) miin hall 1-mufkile?

who solved the-problem

'Who solved the problem?'

(2b) miin Pilli hall 1-mufkile?

who that solved the-problem

'Who solved the problem?'

\footnotetext{
${ }^{6}$ The gloss in examples (2) and (3) are Shlonsky's.
} 
Shlonsky argues that Pilli in (2b) is prompted because the speaker presupposes that there is one having solved the problem. (2a) does not imply such presuppositional effects. Furthermore, Shlonsky states that when the question lacks presupposition, the verb of the interrogative clause can only bear default [3SG.M] agreement. He indicates that this pattern holds true also of Moroccan Arabic, as in (3). ${ }^{7}$

Jkun mfa?

who left(3MS)

'Who left?'

*jkun mfat/ mfaw?

who left.3FS left.3MPL

'Who left?'

$\begin{array}{llll}\text { Jkun lli mfa/ } & \mathrm{m} f \mathrm{at} / & \mathrm{m} f \mathrm{aw} \text { ? } \\ \text { who that left.3MS } & \text { left.3FS } & \text { left(3MPL) } \\ \text { 'Who left?' } & & & \end{array}$

The question in (3a) is grammatical even if Pilli is not used, given that the verb shows default agreement. (3b) is ungrammatical as the verb is inflected for agreement, and Pilli is not used. When the verb is inflected for agreement, Pilli must be used as (3c) demonstrates.

Shlonsky (2002) proposes a bi-clausal analysis of such questions. He claims that questions with Pilli are copular clauses that consist of a subject DP and a predicate, which is here a free relative clause that functions as a nominal predicate providing a definite description, a statement of identity. The wh-phrase is base-generated in Spec TP of the copular clause and then moves to Spec of the higher CP. Consider the schematic representation in (4) (Shlonsky 2002: 152).

Under this proposal, Pilli is treated as $\mathrm{C}^{0}$ that heads the lower CP (see, Cheng 1997 for a different approach and Algryani 2012, among others, for discussion of the two proposals).

\footnotetext{
${ }^{7}$ In Moroccan Arabic Pilli appears reduced as lli.

${ }^{8}$ Several researchers carry over Shlonsky's analysis to other Arabic varieties, while others argue against it, advancing their own proposals. For the former team, see, e.g. Algryani (2012) for Libyan Arabic and Sulaiman (2016) for Syrian Arabic. As for the latter team, see, among others, Gad (2011) and Soltan (2011) for Egyptian Arabic.
} 
(4)

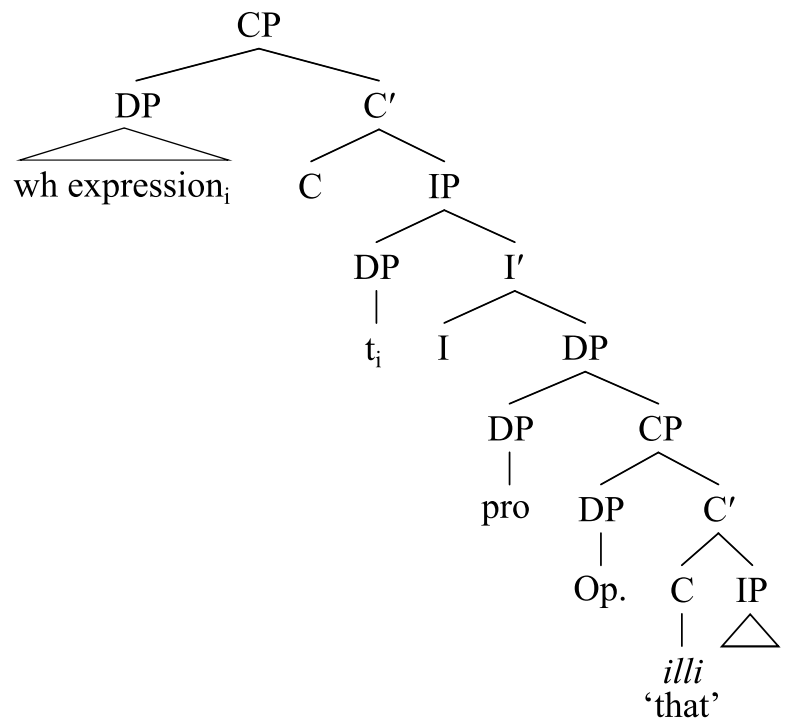

On the other hand, in Jarrah (2017) I take a different tack for JA. I observe that the use of a fronted (non-topicalized) locative or temporal adjunct militates against the use of Pilli in JA even if the verb is inflected for agreement, as exemplified in the following pair.

(5a) miin *(Pilli) ?aұað-at Pal-mafatiiћ Pimbaariћ? who Prt took-3SG.F DEF-keys yesterday 'Who took the keys yesterday?'

(5b) miin Pimbaariћ Paxað-at ?al-mafatiiћ? who yesterday took-3SG.F DEF-keys 'Who took the keys yesterday?'

I propose that Pilli in (5a) fills Spec, SubjP to meet the requirement of the socalled Subject Criterion to have Spec, SubjP filled. Drawing on evidence from several unrelated languages, Rizzi and Shlonsky (2007) argue that Spec, SubjP is a criterial position that it is paired with a criterial property of aboutness, and hence any movement out of this criterial position is barred, a constraint that is known as the Subject Criterion. Due to the effects of this criterion, the extracted subject cannot land in Spec, SubjP en route to the left periphery, as it would 
otherwise get frozen in place and becomes unable to move further. With the presence of mounting evidence that the extracted subject is in the left periphery in JA (e.g. its occurrence to the left of topicalized elements as well as the use of an expletive fiih in existential questions), I propose that the demands of the Subject Criterion is met using Pilli in Spec, SubjP when the thematic subject is extracted. Under this analysis, Pilli is an XP element, given its complementary distribution with the expletive fiih as well as its obligatory occurrence to the right of all de facto left periphery material. Furthermore, I propose that Spec, SubjP can be alternatively filled with a deictic temporal/locative or a pro. This accounts for the lack of Pilli in the presence of inverted locative/temporal adjunct as in (5b) (where the preposed deictic temporal adjunct Pimbaari $\hbar$ is argued to occupy Spec, SubjP, attracted by $\mathrm{Subj}^{\circ}$ ) or the absence of Pilli or a fronted temporal/locative when the verb shows default agreement (i.e. Spec, SubjP is filled with an expletive pro). Furthermore, I observe that locative adjuncts unlike temporal adjuncts can only replace Pilli in questions with unaccusative verbs. ${ }^{9}$

$$
\begin{aligned}
& \text { miin bi-ddukaanah *(Pilli) Paðað-at Pal-mafatiiћ? } \\
& \text { who in-DEF-shop Prt took-3SG.F DEF-keys }
\end{aligned}
$$

$$
\begin{array}{ll}
\text { miin bi-d-dukaanah wigf-at? } & \\
\text { who in-DEF-shop fall down-3SG.F }
\end{array}
$$

'Who fell down in the shop?'

I assume that this follows from the base-generation of temporal and locative adjuncts. Temporal adjuncts are VP-external adjuncts (i.e. TP-adjuncts), whereas locatives are VP-internal adjuncts. Nevertheless, this proposal was taken for granted with no empirical evidence for the position of temporal and locative adjuncts in the clause. From here the current research emerges. Examining facts from left-dislocation, coordination, and ellipsis, this research corroborates the view of the discrepancy between locative and temporal adjuncts with respect to base-generation and hence the difference between them with respect to accessibility to $\mathrm{Subj}^{0}$. Additionally, this research is significant as it shows that this type of inversion is subject to a micro-parametric variation across some Arabic dialects.

\footnotetext{
${ }^{9}$ Locatives are disallowed to replace Pilli in questions with unergative verbs. That should follow from the assumption that $\mathrm{vP}$ in such questions is a phase.
} 


\section{The position of temporal and locative adjuncts}

In this section, I provide evidence from left-dislocation (Section 3.1), coordination (Section 3.2), ellipsis and cross-linguistic evidence (Section 3.3), for the high position of temporal adjuncts and the low position of locatives in the clause whereby they merge.

\subsection{Left-dislocation}

The first piece of evidence that temporal adjuncts are high in the clause and adjoin to TP comes from the observation that such elements are not preposed along with the verb and its object in, among others, sentences with the past tense copula kaan 'was' that occupies mainly $\mathrm{T}^{0}$ in the Arabic sentence (cf., Fassi Fehri 1993, 2012). Consider the following examples from JA (7a represents the unmarked case of the word order in JA).

(7a) Pibin Yamm-i kaan jiSmal bufaar Pimbaarih son uncle-my was.3SG.M make.3SG.M popcorn yesterday 'My cousin was making popcorn yesterday.'

(7b) jiSmal bufaar Pibin Samm-i kaan Pimbaarih make.3SG.M popcorn son uncle-my was.3SG.M yesterday 'Make popcorn is what my cousin did yesterday.'

(7c) *jiSmal bufaar Pimbaarih Pibin Samm-i kaan make.3SG.M popcorn yesterday son uncle-my was.3SG.M Intended: 'Make popcorn is what my cousin did yesterday.'

In (7b), the temporal adjunct Pimbaarih 'yesterday' is not pied-piped along with the verb jiSmal 'making' and the object bufaar 'popcorn', whereas the temporal adjunct is preposed in $(7 \mathrm{c})$, something that leads to the sentence being ungrammatical. This observation can be accounted for suggesting that the complex $\mathrm{V}+\mathrm{O}$ moves to the left periphery (Spec, Focus Phrase, cf. Rizzi 1997) as one unit. Given that the lexical verb in Arabic moves to little $v$ in narrow syntax $\left(\mathrm{V}^{0}\right.$ head-adjoins v ${ }^{0}$, Fassi Fehri 2003, 2012; Balushi 2011; and Alshamari and Jar- 
rah 2016, among many others), it is most likely that the whole phase $\mathrm{v}^{*} \mathrm{P}$ in (7b) is what moves to the left periphery. If the temporal adjunct Pimbaarih 'yesterday' adjoins to $\mathrm{vP} / \mathrm{VP}$, it would be preposed all along with the fronted VO, contrary to fact. The evidence that fronted $\mathrm{VO}$ is one unit occupying one slot in the left periphery comes from the observation that the object cannot appear to the left of the preposed $\mathrm{V}$, as asserted by the ill-formedness of the following sentence.

$$
\begin{aligned}
& \text { *bufaar jiSmal(uh) Pibin Samm-i kaan Pimbaarih } \\
& \text { popcorn make.3SG.M(3SG.M) son uncle-my was.3SG.M yesterday } \\
& \text { 'Make popcorn is what my cousin did yesterday.' }
\end{aligned}
$$

It is hard to account for the ban against the object to appear preverbally in such situations if the two categories would move singly to the left periphery. Notice that ji imal is a head that does not block the movement of an XP category such as the DP object bufaar, given relativized minimality (Rizzi 1990, 2013). On the other hand, the ungrammaticality of sentence (8) is automatically explained under the proposal that $\mathrm{VO}$ moves to $\mathrm{CP}$ as one unit. By extending the proposal that there is no sub-extraction out of a previously moved domain (Stepanov 2001: 52, following Wexler and Culicover's (1980) Freezing Principle) to JA, the ungrammaticality of sentence (8) follows. The object is sub-extracted out of the $\mathrm{v}^{*} \mathrm{P}$ phase which already moves to the left periphery. Consider the schematic representation in (9). ${ }^{10}$

The object is not allowed to move out of the $\mathrm{v}^{*} \mathrm{P}$, while the latter occupies Spec, Focus Phrase. As shown in tree (9), the temporal adjunct Pimbaarih 'yesterday' adjoins to TP. Hence, the ban against its movement along with $\mathrm{v}^{*}$ P material is motivated. ${ }^{11}$ Given that moves to the left periphery is the whole phrase (vP), the linear order between the verb and the object remains intact in their new position in the left periphery. Additionally, the assumption that verb and the object in (7b) are not part of one phrasal unit in the left periphery is undermined by the fact that VO material is not discontinuous. Consider the following example, where the locative adjunct Pibdaarna 'at our house' intervenes between the verb and the object, a matter that yields ungrammaticality.

\footnotetext{
${ }^{10}$ Note that Spec, SubjP is filled with the thematic subject Pibin Samm-i.

${ }^{11}$ I depart here from Kayne's (1994) Linear Correspondence Axiom and follow, instead, Abels and Neeleman's (2006) proposal that allows for right adjunction (resulted from base-generation).
} 
(9)

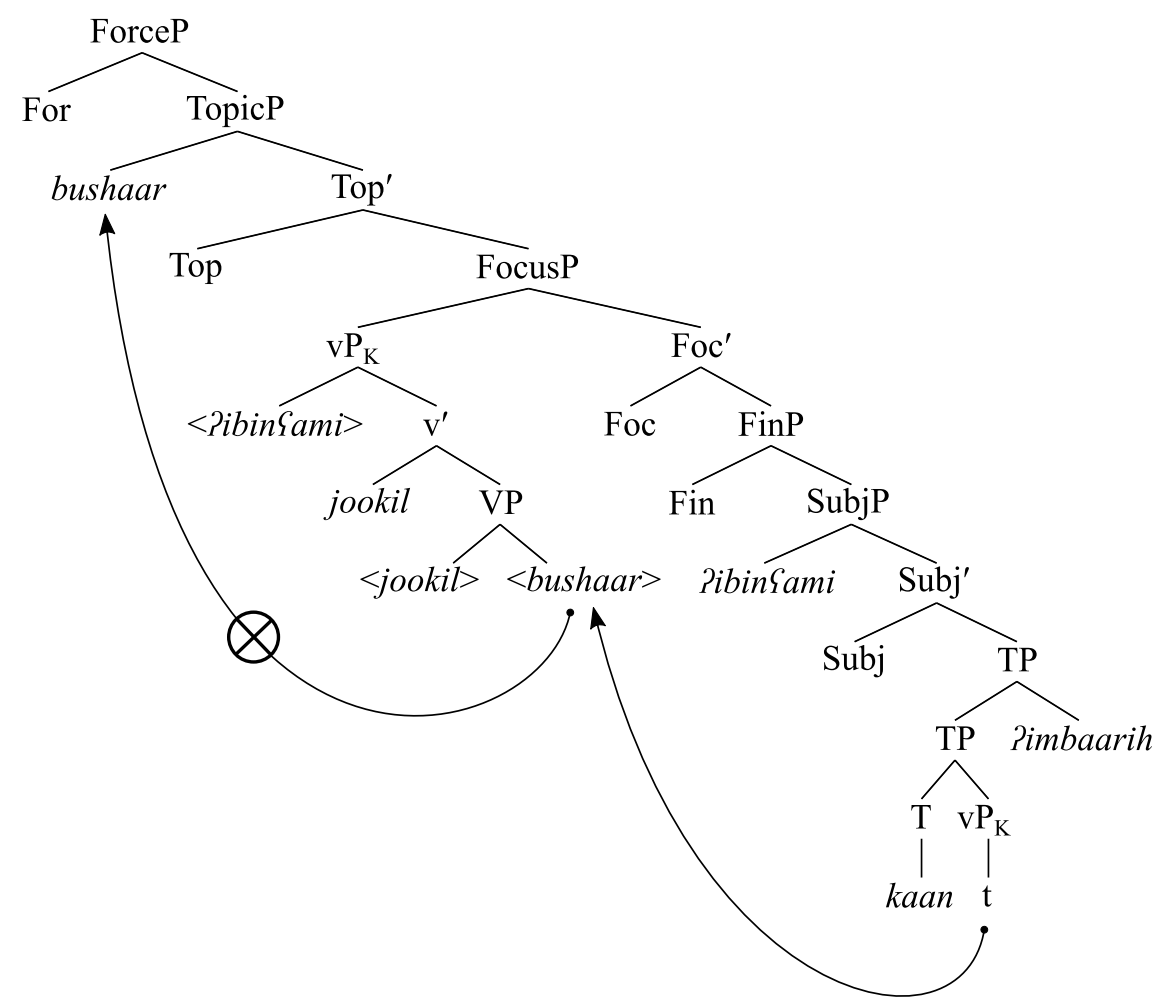

(10) *jiSmal Pib-daar-na bufaar Pibin Camm-i kaan make.3SG.M at-house-our popcorn son uncle-my was.3SG.M Pimbaarih yesterday

'Make popcorn at our house is what my cousin did yesterday.'

Along these lines, there exists strong evidence that sentences with VOST word order (where T stands for Tense) involve VO phrasal movement to the left pe- 
riphery. Had temporal adjuncts adjoined to VP, they would have preposed along with $\mathrm{v} * \mathrm{P}$ rather than being stranded, contrary to fact.

On the other hand, the situation in $(7 \mathrm{a}, \mathrm{b})$ appears not to be the case with respect to the locative adjunct Pibdaarna 'at our house'. The situation is actually reversed, as demonstrated in the following examples.

(11a) Pibin Samm-i kaan jiSmal bufaar Pib-daar-na
son uncle-my was.3SG.M make.3SG.M popcorn at-house-our
'My cousin was making popcorn at house our.'
(11b)
*jiSmal bufaar Pibin Samm-i kaan Pib-daar-na
make.3SG.M popcorn son uncle-my was.3SG.M at-house-our
'Making popcorn at our house is what my cousin did.'
(11c) jiSmal bufaar Pib-daar-na Pibin Samm-i kaan
make.3SG.M popcorn at-house-our son uncle-my was.3SG.M
'Making popcorn at our house is what my cousin did.'

Sentence (11b) is ill-formed as the locative adjunct Pibdaarna appears to the right of the past tense copula kaan, while sentence (11b) is grammatical with the dislocation of the locative along with verb and the accompanying object. The behaviour of the locative adjunct Pibdaarna in the aforesaid examples in (11) is strongly indicative of the fact that locatives adjoin to VP and thus should be preposed when the $\mathrm{vP}$ is fronted as one unit (to the left periphery). ${ }^{12}$ In view of this, it can be concluded that temporal adjuncts adjoin to a different projection than locative adjuncts. I argue that temporal adjuncts adjoin to TP, while locatives adjoin to VP.

In the following section, I provide a further line of evidence from coordination in favour of the view that locatives adjoin to VP, whereas temporal adjuncts adjoin to TP.

\subsection{Coordination}

Empirical support to the proposal that temporal adjuncts adjoin to TP can also be offered by facts from coordination in JA. When two constituents (i.e. con-

\footnotetext{
${ }^{12}$ It is worth noting here that a locative cannot also occur to the left of the fronted verb, an observation that supports our proposal that the locative is part of the moved material and hence lends credence to Wexler and Culicover's (1980) Freezing Principle.
} 
juncts) involve each a temporal adjunct, they must consist of at least as much structure as TP. This observation becomes clearer again in the context of the past tense copula kaan. Consider the example in (12).

$\begin{array}{lllll}\text { Paboo-i } & \text { kaan } & \text { Piwaddi } & \text { Paхoo-i } & \text { Piz-zabiir } \\ \text { father-my } & \text { was.3SG.M } & \text { send.3SG.M } & \text { brother-my } & \text { DEF-young }\end{array}$

Ga-1-midrasih Pissaaßah sabৎah Pis ubuћ w-*(kaan) to-DEF-school hour seven morning and-was.3SG.M

jigra? Pidzdzariidah Pissaaßah tişah Pis`ubuћ read.3SG.M newspaper hour nine morning

'My father was taking my younger brother to the school at $7 \mathrm{AM}$ and was reading the newspaper at 9 AM.'

Here the second kaan is obligatory as long as the temporal adjunct PissaaSah tişah Pis' $u b u \hbar$ ' at $9 \mathrm{AM}$ ' is used in the second conjunct. This observation bears implication for the position of temporal adjuncts in the clause. Suppose that temporal adjuncts are only licensed if they adjoin to TP; their occurrence in the clause thus requires the projection of TP which in turn can house kaan. ${ }^{13}$ Following Williams's (1978) Law of Coordination of Likes (a constraint that demands the conjuncts be of the same syntactic category), ${ }^{14}$ sentence (12) involves two coordinated TP's, each headed by the past tense copula kaan. If kaan had been dropped out of the second conjunct, the coordination conjunction $w$ would conjoin two vP's in the presence of kaan in the first conjunct. It is a wellestablished assumption across Arabic dialects that the imperfective does not head-move to $\mathrm{T}^{0}$; the mere presence of this form of the verb in the second conjunct is thus never indicative of TP (cf. Benmamoun 1999, 2000). Accordingly, the second conjunct must project TP to license the temporal adjunct (and should be in the past to be felicitously equivalent of the first conjunct).

Now, let's throw light on cases with locatives. Consider the example in (13).

\footnotetext{
${ }^{13}$ This discussion gives rise to Eisele's (1988) old assumption that temporal adverbs/adjuncts are anchored in the sentence by tense. See also Shlonsky (1997: 31) for a similar argument.

${ }^{14}$ See van Koppen and Rooryck (2008) for a feature-based reinterpretation of Williams's (1978) Law of Coordination of Likes.
} 
'My father was taking watching the match at home and (was) reading the newspaper at the supermarket.

That kaan is optional in (13) is supportive evidence that locatives are not licensed in their clauses by TP. Following the proposal that locatives adjoin to VP, their presence is not tied to TP, and hence whether kaan is present or not becomes irrelevant for their licensing, unlike the case of temporal adjuncts. Actually, this discussion provides us with an answer of why some verbs, e.g. put, sub-categorize for locatives, while there are no verbs, to the best of my knowledge, that subcategorize for temporal adjuncts. A verb does not subcategorize for an element which it does not license.

In the following section, I present further evidence from ellipsis for the low position of locatives and the high position of temporal adjuncts.

\subsection{Ellipsis}

Another case in favour of the proposal on locative vs. temporal base-generation has to do with ellipsis. Consider the following two examples where the second conjunct undergoes VP deletion.

(14a) Balqees kaan-t tursum Sarah Pimbaarih w-hashem

Balqees was-3SG.F draw.3SG.F Sarah yesterday and-Hashem

kaan Pawal Pimbaarih

was.3SG.M First yesterday

'Balqees was drawing Sarah yesterday, and Hashem was doing so the day before yesterday.'

(14b) *Balqees kaan-t tursum Sarah bi-l-beet w-hashem Balqees was-3SG.F draw.3SG.F Sarah at-DEF-house and-Hashem 


\section{kaan bi-1-hadiigah}

was.3SG.M at-DEF-garden

Intended: 'Balqees was drawing Sarah at our house, and Hashem was doing so in the garden.'

As the temporal adjunct ?awal ?imbaarih 'the day before yesterday' adjoins to $\mathrm{TP}$, its occurrence is not affected by deletion of VP, as illustrated in (14a). On the other hand, sentence (14b) is ill-formed because of the presence of the locative adjunct bilhadiigah 'in the garden', which is expected not to appear when VP deletes.

A similar observation is reported in Moroccan Arabic (MA). Kortobi (2002) shows that when the adverb in MA is a TP-adverb, it is adjoined to TP, which is higher than Aspect Phrase (AspP). It follows that when AspP deletes, time adverbials can stay, as it is unaffected by deletion (see 15a below). On the other hand, manner adverbs are affected by deletion, given that they are anchored by AspP (see 15b). (The two examples are adapted from Kortobi 2002: 233-234.)

(15a) ?Yasin kan ka-y ${ }^{c} u m \quad$ lbarəћ $\quad$ w-Yousre kan əwwel lbarəћ.

Yasin was PROG-swim yesterday and-Yousre was ___ day before 'Yousef was swimming yesterday, and Yousre was doing so the day before.'

(15b) *Yasin kan ka-yakul bəzzərba w-Yousre kan _ bfswiya. Yasin was PROG-eat fast and-Yousre was _ slowly

'Yasin was eating fast and Yousre was doing so slowly.'

It is therefore reasonable to conclude that temporal adjuncts adjoin to TP, whereas locative adjuncts adjoin to a lower position, i.e. VP.

From a cross-linguistic point of view, one finds a plethora of examples from natural languages (unrelated to Arabic) advocating this view. A case in point here is Modern Greek. Rivero (1992: 291) correctly notes that a clear dichotomy between adverbs that function as VP-modifiers internal to the VP and those that are external to the VP can be established in Modern Greek. She argues that the former includes locatives and adverbs that are related to the modification of the action expressed by the verb or Aktionsart, ${ }^{15}$ whereas the latter includes time

\footnotetext{
${ }^{15}$ Traditional European structuralist studies of languages establish a semantic division between $A s-$ pect and Aktionsart or 'kind of action' (see Bache 1982). Rivero (1992: 304) states that Aspect re-
} 
adverbs. Rivero's argumentation hinges on the observation that the former class of adverbs may incorporate into the verb (i.e. the adverb occurring strictly before the verb forming a grammatical morphological unit), whilst the latter class of adverbs fail to incorporate, as evidenced by the contrast in the following examples from Modern Greek:

(16a) I Maria tha to girisi anapoda the Mary will it turn upside+down 'Mary will turn it upside down.'

(16b) I Maria tha to anapodo- girisi

The Mary will it upside + down-turn

'Mary will turn it upside down.'

(The two examples are from Rivero 1992: 289.)

(16c) I ginekes den kapnizun tora the women not smoke now 'Women do not smoke now.'

(16d) *I ginekes den tora-kapnizun the women not now-smoke 'Women do not smoke now.'

(The two examples from Rivero 1992: 314.)

In (16b), the adverb anapoda 'upside-down' incorporates with the verb girisi 'turn', both forming one morphological unit. On the other hand, (16d) is indicative of the impossibility of incorporation of time adverb into the verb. The time adverb tora 'now' is prohibited to occur strictly before the verb kapnizun 'smoke', failing to incorporate, i.e. to form one grammatical morphological unit with the verb. The same observation extends to other time adverbs that refer to deictic points in time, including xthes 'yesterday' and avrio 'tomorrow'. For Rivero, the examples in (16) are strong evidence that time adverbs are base-

fers to the dichotomy often labelled Perfective/Imperfective. On the other hand, Aktionsart refers to the characteristics of the inherent meaning of verbs and the internal properties of States of Affairs as expressed by predicates. Distinction between states (e.g. know), achievements (e.g. reach the summit), activities (e.g. run) are under Actionsart (see Vendler 1967; Comrie 1972; and Grimshaw 1990). 
generated VP-externally, and they modify inflectional layers that encode Tense (p. 296). ${ }^{16,17}$

With this being the case, it can be concluded that temporal adjuncts occupy a high position in the clause, whereas locative adjuncts adjoin to their clause in a lower position. Said this, the restriction against locatives to occupy Spec, SubjP in transitive (and unergative) clauses can be accounted for. Chomsky (2001, and 2008) argues that clause derivation proceeds by phases. Typical phases are the propositional categories: $\mathrm{CP}$ and $\mathrm{v} * \mathrm{P}$. Consider the following representation:

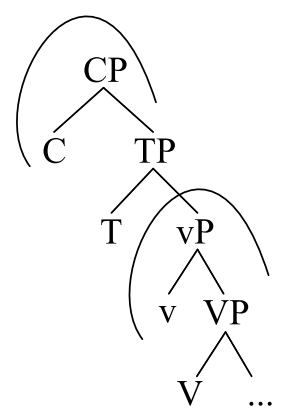

Most relevant here is the so-called Phase Impenetrability Condition (PIC), which is a constraint that contributes to efficient computation (see Müller 2011). This condition constrains accessibility of phase materials to higher probes; only the head and the edge of the phase are accessible to a higher probe. The PIC is formulated as follows.

(18) The domain of a head X of a phase XP is not accessible to operations outside XP; only $\mathrm{X}$ and its edge are accessible to such operations. (Chomsky 2001: 13).

\footnotetext{
${ }^{16}$ See Koster (1986) and Ojea Lopez (1994) for similar arguments in Italian and Spanish, respectively. See also Stroik (1990) for further evidence that locatives are VP-internal entities.

${ }^{17}$ Cinque (1999) does not postulate a specific "fixed" position for temporal adjuncts. He just mentions that deictic temporal adverbs such as now and then are base-generated in a position different from that of other temporal adverbs (Cinque 1999: 87). However, see Frey (2000: 113) and Ernst (2001: ch. 7) for counterarguments to Cinque's (1999) proposal. These two authors argue that temporal adjuncts are base-generated in positions high in the clause structure.
} 
For instance, due to the PIC, the edge of $\mathrm{v} * \mathrm{P}$ and the head $\mathrm{v}$ are accessible to $\mathrm{Subj}^{0}$, as schematically presented in (19). ${ }^{18}$

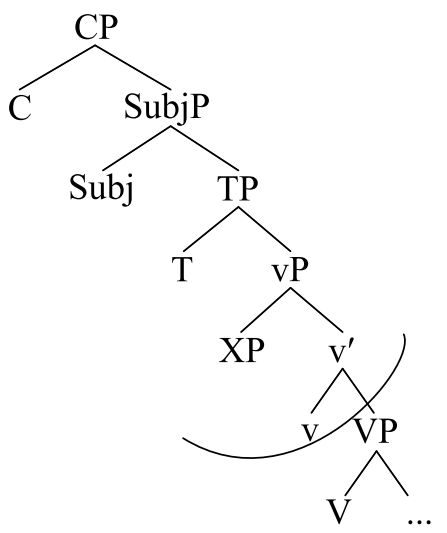

Let's explore how this line of analysis accounts for locative/temporal inversion when the subject is extracted. In case of temporal adjuncts, they are adjoined to TP. It follows that they are always accessible to Subj to fill Spec, SubjP following the demands of the Subject Criterion. In other words, the temporal adjuncts' high position being adjoined to TP makes them impervious to the type of the verb (transitive vs. intransitive). On the other hand, locatives being adjoined to VP are subject to the effects of the PIC. Subj ${ }^{0}$ cannot attract them in the presence of $\mathrm{v}^{*} \mathrm{P}$ unless they are at the edge of $\mathrm{V}^{*} \mathrm{P}$. This amounts to saying that locatives must vacate their base-generation position and raise to the edge of $\mathrm{v}^{*} \mathrm{P}$ to be within the accessible domain of $\mathrm{Subj}^{0}$. The question that arises here is why locatives do not raise to the edge of $\mathrm{v} * \mathrm{P}$, so they can be an accessible strategy to fill Spec, SubjP. The answer to this questions lies in the lack of motivation to do so. That Spec, SubjP must be filled does not demand a matching feature on the category that occupies it. There is no [SUBJ] feature, unlike [TOP] or [FOC]

\footnotetext{
${ }^{18}$ Note here that Chomsky (2001) argues that XP becomes a phase once the next phase head is introduced. Following this, the whole spectrum of attractors located between $\mathrm{v}$ and $\mathrm{C}$ (including $\mathrm{Subj}^{\circ}$ ) would be allowed to reach VP-adjoined adjuncts before $\mathrm{C}$ enters the derivation, as noted by an anonymous reviewer. My answer to this problem is the hypothesis that the [EPP] feature on $\mathrm{Subj}^{\circ}$ is passed down from $\mathrm{C}^{\circ}$, being a phase head. See Chomsky (2007) for that EPP, agreement and Tense features (among others) are not a property of $\mathrm{T}$ or other heads but $\mathrm{C}^{\circ}$. Following this hypothesis, $\mathrm{Subj}^{\circ}$ can only attract adjuncts which are adjoined to the $\mathrm{v}^{*} \mathrm{P}$ edge, i.e. $\mathrm{Subj}^{\circ}$ is an attractor only when $\mathrm{C}^{\circ}$ appears in the derivation.
} 
that must be part of the featural bundle of the element that fills Spec, Topic Phrase or Spec of Focus Phrase, respectively. This line of analysis, if correct, accounts for why locative/temporal inversion yields no change in the interpretation of the question at issue. ${ }^{19}$ By contrast, when there is no phrase boundary between $\mathrm{Subj}^{0}$ and the locative, a state of affairs found with unaccusative predicates, nothing can prevent the former from attracting the latter, a mater that leads to locative inversion.

Having discussed the evidence that temporal adjuncts adjoin to TP, whereas locative adjoin to VP, let's explore whether temporal/locative inversion is used in other Arabic dialects.

\section{Temporal/locative inversion across Arabic dialects}

The question that suggests itself here is whether temporal/locative inversion is an idiosyncratic property of JA or a permissible strategy whose effect can be discerned in other Arabic dialects. In order to answer this question, I examine data from two Arabic varieties: Iraqi Arabic (IA) and Najdi Arabic (NA). Data reveals that temporal/locative inversion is used in IA, whereas it is not allowed in NA. As a step prior to this investigation, it is instructive to note that temporal and locative adjuncts merge in the same position in IA and NA in comparison to $\mathrm{JA}$, as they give rise to the same (un)grammaticality. Consider first the examples from left-dislocation (examples in (20) from NA, and examples in (21) from IA).

\begin{tabular}{|c|c|}
\hline a) & $\begin{array}{l}\text { Pibin Samm-i kaan jSamil fufaar Pams } \\
\text { son uncle-my was.3SG.M make.3SG.M popcorn yesterday } \\
\text { 'My cousin was making popcorn yesterday.' }\end{array}$ \\
\hline $20 \mathrm{~b})$ & $\begin{array}{l}\text { jSamil fufaar Pibin Samm-i kaan Pams } \\
\text { make.3SG.M popcorn son uncle-my was.3SG.M yesterday } \\
\text { 'Making popcorn is what my cousin did yesterday.' }\end{array}$ \\
\hline c) & $\begin{array}{l}\text { fufaar Pams Pibin Camm-i kaan } \\
\text { a popcorn yesterday son uncle-my was.3SG.M }\end{array}$ \\
\hline
\end{tabular}

\footnotetext{
${ }^{19}$ This discussion gives rise to the question whether filling Spec, SubjP occurs at PF rather than in narrow syntax. The subject criterion demands Spec, SubjP be filled with some category, irrespective of its content, whence the use of pleonastic elements.
} 
(21a) Pibin Samm-i t faan js haawi faamijjah Pil-baarha son uncle-my was.3SG.M make.3SG.M popcorn yesterday 'My cousin was making popcorn yesterday.'

(21b) jshaawi Jaamijjah Pibin Samm-i tfaan Pil-baarha make.3SG.M popcorn son uncle-my was.3SG.M yesterday 'Making popcorn is what my cousin did yesterday.'

(21c) *jshaawi faamijjah Pil-baarha Pibin Samm-i t faan make.3SG.M popcorn yesterday son uncle-my was.3SG.M Intended: 'Making popcorn is what my cousin did yesterday.'

In the two dialects, the given temporal adjunct must remain to the right of the past tense copula; otherwise the resulting sentence would be ungrammatical. When the temporal adjunct is replaced with a locative adjunct; the situation is switched. Consider the following examples (the examples of (22) from NA; examples of (23) from IA).

(22a) *jifmal fufaar Pibin Samm-i kaan Pib-daar-na make.3SG.M popcorn son uncle-my was.3SG.M at-house-our 'Making popcorn at our house is what my cousin did.'

(22b) j̧amil fufaar Pib-daar-na ?ibin Samm-i kaan make.3SG.M popcorn at-house-our son uncle-my was.3SG.M 'Making popcorn at our house is what my cousin did.'

(23a) *jshaawi faamijjah Pibin Samm-i tfaan Pib-daar-na make.3SG.M popcorn son uncle-my was.3SG.M at-house-our 'Making popcorn at our house is what my cousin did.'

(23b) jshaawi Jaamijjah Pib-daar-na Pibin Samm-i tfaan make.3SG.M popcorn at-house-our son uncle-my was.3SG.M 'Making popcorn at our house is what my cousin did.'

The ungrammaticality of sentences (22a and 23a) on the one hand and the grammaticality of (22b) and (22b) on the other hand are evidence that locatives are VP-internal adjuncts. In addition, NA and IA behave identically with respect to the coordination facts in comparison to JA. Consider the following examples ((24) - NA; (25) - IA). 


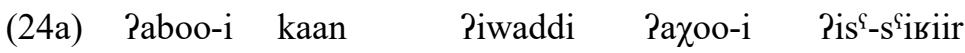
father-my was.3SG.M sent.3SG.M brother-my DEF-young la-1-madrisah PassaaYah sabৎah Pas`ubuћ w-*(kaan) to-DEF-school hour seven morning and-was.3SG.M yagra? Pal-dziriidah ?assaa@ah tişah ?as'ubuh read.3SG.M newspaper hour nine morning 'My father was taking my younger brother to the school at $7 \mathrm{AM}$ and was reading the newspaper at 9 AM.'

(24b) Paboo-i kaan jitfarrad3 Pal-almubraha bi-l-beet father-my was.3SG.M watch.3SG.M DEF-match-my in-DEF-house w-(kaan) yigra? Pidzariidah bi-l-maћall and-was.3SG.M read.3SG.M newspaper in-DEF-supermarket 'My father was taking watching the match at home and (was) reading the newspaper at the supermarket.'

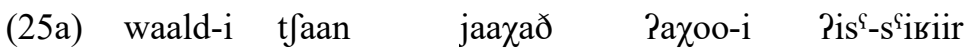
father-my was.3SG.M sent.3SG.M brother-my DEF-young

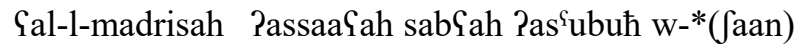
to-DEF-school hour seven morning and-was.3SG.M yiqro Pal-dziriidah Passaałah tişah Pas ubuћ read.3SG.M DEF-newspaper hour nine morning 'My father was taking my younger brother to the school at $7 \mathrm{AM}$ and was reading the newspaper at 9 AM.'

(25b) waald-i tfaan jitfarrad3 Pal-almubraha bi-l-beet father-my was.3SG.M watch.3SG.M DEF-match-my in-DEF-house w-(kaan) yiqro Pal-dziriidah bi-l-maћall and-was.3SG.M read.3SG.M DEF-newspaper in-DEF-supermarket 'My father was taking watching the match at home and (was) reading the newspaper at the supermarket.

I extend my analysis of JA sentences to the examples in (24) and (25). The past tense copula is obligatory when the conjunct includes a temporal adjunct, im- 
plying that temporal but not locative adjuncts are licensed in the clauses being adjoined to TP. Ellipses behaves similarly, as asserted from the examples below. (The examples of (26) from NA; examples of (27) from IA.)

(26a) Balqees kaan-t tarsum Sarah Pams w-hashem

Balqees was-3SG.F painting Sarah yesterday and-Hashem

kaan qabul ?ams

was.3SG.M first yesterday

'Balqees was painting yesterday, and Hashem was doing so the day before yesterday.'

(26b) *Balqees kaan-t tarsum Sarah ba-l-beet w-hashem Balqees was-3SG.F painting Sarah at-DEF-house and-Hashem

kaan ba-l-hadiigah

was.3SG.M at-DEF-garden

Intended: 'Balqees was painting at our house, and Hashem was doing so in the garden.'

(27a) Balqees tfaan-it tirsim Sarah Palbaarhə w-hashem

Balqees was-3SG.F painting Sarah yesterday and-Hashem

tfaan Pawal ?albaarhə

was.3SG.M first yesterday

'Balqees was painting yesterday, and Hashem was doing so the day before yesterday.'

(27b) *Balqees tfaan-it tarsum Sarah ba-l-beet w-hashem Balqees was-3SG.F painting Sarah at-DEF-house and-Hashem tfaan ba-l-hadiigah was.3SG.M at-DEF-garden

Intended: 'Balqees was painting at our house, and Hashem was doing so in the garden.'

As it appears, JA, NA, and IA all behave the same way with the respect to the position of locative and temporal adjuncts. Locative adjuncts are low elements adjoin to VP, whilst temporal adjuncts are high elements adjoin to TP. The ques- 
tion now is whether temporal locative inversion occurs also in these dialects. The data reveal that IA is similar to JA in that temporal/locative inversion militates against the use of Pilli, whereas NA behaves differently in that temporal/locative inversion results in ungrammaticality ( 25 - NA; $26-$ IA).

*man *(Pilli) Pams Pixað-t Pal-mafatiiћ?

who Prt yesterday took-3SG.F DEF-keys

'Who took the keys yesterday?'

b. miin *(2illi) bi-d-dukaanah wigৎ-at?

who Prt in-DEF-shop fall down-3SG.F

'Who fell down in the shop?'

(29a) menu Pil-baarha Pixað-t Pal-mafatiiћ?

who yesterday took-3SG.F DEF-keys

'Who took the keys yesterday?'

(29b) menu bi-d-dukaanah wigh-at?

Who in-DEF-shop fall down-3SG.F

'Who fell down in the shop?'

The example in (28a) demonstrates that the temporal inversion does not salvage the ungrammaticality of the question, hence the obligatory use of the D-linking particle Pilli. On the other hand, IA lines up with JA in that temporal inversion can fill Spec, SubjP. It can be concluded that temporal/locative inversion is not always a legitimate strategy to fill Spec, SubjP in all Arabic dialects. NA does not avail itself of this strategy. Temporal/locative inversion is as such subject to a micro-parametric inversion across Arabic dialects. This might be related to some restriction on the element occurring in Spec, SubjP in the dialects that do not allow for temporal/locative inversion. It is the task of any future work addressing this point to reveal the exact nature of this restriction. This would essentially be a step closer to understanding the cross-linguistic aspects of the phenomenon of subject extraction.

\section{Conclusion}

The aim of this research was twofold. First, it has attempted to provide empirical evidence supporting the view that temporal adjuncts adjoin to their clause in 
a position different from that of the locative adjuncts. All facts from leftdislocation, coordination and ellipsis point to the conclusion that temporal adjuncts adjoin to TP, whereas locatives adjoin to VP. Such a difference between these two types of adjuncts with respect to base-generation accounts for their nuanced behaviour concerning filling Spec, SubjP. Given their high position, temporal adjuncts are accessible strategy to fill Spec, SubjP, regardless of the verb transitivity. On the contrary, locatives adjuncts are limited to fill Spec, SubjP when the verb is unaccusative as there is no phase boundary that prevents $\mathrm{Subj}^{0}$ from attracting it, given the effects of the PIC. Second, this research has explored examples from other two Arabic dialects, namely NA and IA to examine whether temporal/locative inversion is a strategy used across other dialects. The examination reveals that NA does not pattern with JA and IA in using this strategy even though the types of adjuncts behave the same way as in JA and IA. This points to the conclusion that temporal/locative inversion is subject to a micro-parametric variation across Arabic dialects.

\section{References}

Abels, K. and A. Neeleman. 2006. Universal 20 without the LCA. (Ms., University of Tomso and University College London.)

Algryani, A. 2012. The syntax of ellipsis in Libyan Arabic: A generative analysis of sluicing, VP ellipsis, stripping and negative contrast. (PhD dissertation, Newcastle University.)

Alshamari, M. and M. Jarrah. 2016. "A minimalist-based approach to phrasal verb movement in North Hail Arabic". International Journal of English Linguistics 6. 24-37.

Bache, C. 1982. “Aspect and Aktionsart: Towards a semantic distinction". Journal of linguistics 18(1). 57-72.

Balushi, R. 2011. Case in Standard Arabic: The untraveled paths. (PhD dissertation, University of Toronto.)

Benmamoun, E., 1999. “Arabic morphology: The central role of the imperfective." Lingua 108. 175-201.

Benmamoun, E. 2000. The feature structure of functional categories: A comparative study of Arabic dialects. Oxford, Oxford University Press

Cardinaletti, A. 2004. "Towards a cartography of subject positions". In: Rizzi, L. (ed.), The structure of CP and IP. New York: Oxford University Press. 115-165.

Cheng, L.L. 1997. On the typology of wh-questions. New York: Garland

Chomsky, N. 2000. "Minimalist inquiries: The framework". In: Martin, M. and J. Uriagereka (eds.), Step by step: Essays in minimalist syntax in honor of Howard Lasnik. Cambridge, MA: MIT Press. 89-156. 
Chomsky, N. 2001. "Derivation by Phase". In: Kenstowicz, M. (ed), Ken Hale: A life in language. Cambridge, MA: MIT Press. 1-52.

Chomsky, N. 2007. "Approaching UG from below”. In: Gartner, H. and U. Sauerland (eds.), Interfaces + recursion = language? Chomsky's minimalism and the view from syntax-semantics. Berlin: Mouton de Gruyter. 1-30.

Chomsky, N. 2008. "On phases”. In: Freidin, R., C.P. Otero and M.L. Zubizarreta (eds.), Foundational issues in linguistic theory. Essays in honor of Jean-Roger Vergnaud. Cambridge, MA: MIT Press. 291-321.

Cinque, G. 1999. Adverbs and functional heads. Oxford: Oxford University Press.

Comrie, B. 1976. Aspect: An introduction to the study of verbal aspect and related problems (vol. 2). Cambridge: Cambridge University Press.

Eisele, J. 1988. The syntax and semantics of tense, aspect and time reference in Cairene Arabic. (PhD dissertation, University of Chicago.)

Ernst, T., 2001. The syntax of adjuncts. Cambridge: Cambridge University Press.

Fassi Fehri, A. 1993. Issues in the structure of Arabic clauses and words. Dordrecht: Kluwer.

Fassi Fehri, A. 2003. "Verbal plurality, transitivity, and causativity". In: Lecarme, J. (ed.), Research in Afroasiatic grammar II: Selected papers from the Fifth Conference on Afroasiatic Languages, Paris. Amsterdam: John Benjamins. 151-185.

Fassi Fehri, A. 2012. Key features and parameters in Arabic grammar. Amsterdam: John Benjamins.

Fernández, J. 2009. "On the composite nature of subject islands: A phase-based approach”. SKY Journal of Linguistics 22. 91-138.

Frey, W. 2000. "Syntactic requirement on adverbs". In: Fabricius-Hansen, C., E. Lang and C. Maienborn (eds.), Approaching the grammar of adjuncts (ZASPIL 17). Belin: ZAS. 107-134.

Gad, R.F.G.A. 2011. A syntactic study of wh-movement in Egyptian Arabic within the Minimalist Program. (PhD dissertation, University of Leeds.)

Grimshaw, J. 1990. Argument structure. Cambridge, MA: MIT Press.

Jarrah, M. 2017. "A criterial freezing approach to subject extraction in Jordanian Arabic". Canadian Journal of Linguistics/Revue canadienne de linguistique 62(3). 411-448.

Kayne, R. 1994. The antisymmetry of syntax. Cambridge, MA: MIT Press.

Koppen, M. van and J. Rooryck. 2008. Resolving resolution: underspecification and the law of coordination of likes. (Ms., Utrecht University and Leiden University.)

Kortobi, I. 2002. "Gapping and VP-deletion in Moroccan Arabic". In: Ouhalla, J. and U. Shlonsky (eds.), Themes in Arabic and Hebrew syntax. Dordrecht: Kluwer Academic Publishers. 217-240.

Koster, J. 1986. The relation between pro-drop, scrambling, and verb movements. (Ms., Rijksuniversiteit Groningen.)

Müller, G., 2011. Constraints on displacement: A phase-based approach. Amsterdam: John Benjamins Publishing.

Ojea López, A.I. 1994. “Adverbios y categorías funcionales en español”. Revista Española de Lingüística 24. 393-416.

Rivero, M.L. 1992. "Adverb incorporation and the syntax of adverbs in Modern Greek". Linguistics and philosophy 15. 289-331. 
Rizzi, L. 1990. Relativized minimality. Cambridge, MA: MIT Press

Rizzi, L. 1997. "The fine structure of the left periphery". In: Haegeman, L. (ed.), Elements of grammar. Dordrecht: Kluwer. 281-337.

Rizzi, L. 2005. “On some properties of subjects and topics”. In: Brugé, L., G. Giusti, N. Munaro, W. Schweikert and G. Turano (eds.), Proceedings of the XXX Incontro di Grammatica Generativa, Cafoscarina, Venice, Italy.

Rizzi, L. 2010. "On some properties of criterial freezing”. In: Panagiotidis, E.P. (ed.), The complementizer phrase. Oxford: Oxford University Press. 17-32.

Rizzi, L. 2013. "Locality”. Lingua 130. 169-186.

Rizzi, L. 2014. “Some consequences of criterial freezing”. In: Svenonius, P. (ed.), Functional structure from top to toe: The cartography of syntactic structures. Oxford: Oxford University Press. 19-46.

Rizzi, L. and U. Shlonsky. 2007. "Strategies of subject extraction”. In: Gärtner, H. and U. Sauerland (eds.), Interfaces + recursion = language? Chomsky's minimalism and the view from syntax-semantics. Berlin: Mouton de Gruyter. 115-160.

Shlonsky, U. 1997. Clause structure and word order in Hebrew and Arabic: An essay in comparative Semitic syntax. New York: Oxford University Press.

Shlonsky, U. 2002. "Constituent questions in Palestinian Arabic". In: Ouhalla, J. and U. Shlonsky (eds.) Themes in Arabic and Hebrew syntax. Dordrecht: Kluwer. 137155.

Soltan, U. 2011. "On issues of Arabic syntax: An essay in syntactic argumentation". Brill's Journal of Afroasiatic Languages and Linguistics 3. 236-280.

Stepanov, A. 2001. Cyclic domains in syntactic theory. (PhD dissertation, University of Connecticut.)

Stroik, T. 1990. “Adverbs as V-sisters.” Linguistic Inquiry 21. 654-661.

Sulaiman, M. 2016. The syntax of wh-questions in Syrian Arabic. (PhD dissertation, Newcastle University.)

Vendler, Z. 1967. Linguistics and philosophy. Ithaca, NY: Cornell University Press.

Wexler, K. and P. Culicover. 1980. Formal principles of language acquisition. Cambridge, MA: MIT Press.

Williams, E. 1978. "Across the board rule application”. Linguistic Inquiry 9. 31-43.

\section{Address for correspondence:}

Marwan Jarrah

Department of Linguistics

School of English Language, literature, and linguistics

Newcastle University

15 Angerton Gardens

Newcastle NE5 2JA

United Kingdom

m.a.s.jarrah@ncl.ac.uk 